\title{
O trabalho como fundamento para a transformação da concepção de tempo formada a partir do livro didático de história
}

Simone Varela *

\section{RESUMO}

Neste artigo o objetivo central é apresentar uma proposta para o Ensino de História que considere as relações sócio-históricas efetivas durante o processo de ensino-aprendizagem da História. A partir do pressuposto defendido, os conteúdos escolares contidos no livro didático, dentre eles o tempo, precisam considerar as características sócio-históricas das sociedades estudadas. Para que isto ocorra, o trabalho e o tempo histórico precisam estar caracterizados como eixos, pelos quais a análise histórica deve ocorrer.

Palavras-chave: Ensino de História; Livro didático; Tempo histórico; Trabalho.

\section{Introdução}

[...] o mercado revigora a sociedade capitalista, apropriando-se de maneira cabal do tempo e do espaço sócio-individuais. Sua força advém de sua capacidade para oferecer um modelo de totalidade social, um modelo apoiado diretamente na experimentação espaço-temporal, e na reelaboração dos conceitos decorrentes destas duas categorias. [...] disciplina científica do trabalho e, com ela, os hábitos, habilidades, valores e conceitos formados envolvem, diretamente, a questão do tempo. 0 capital trava uma batalha por minutos. Uma cronologia recriada para servir à reprodução do capitalismo e não do indivíduo na sociedade. [...] com o lixo, descartam-se modos de pensar e de ser. Na compreensão do tempo e do espaço, na aceleração do impulso social, na valorização da instantaneidade, a experiência individual é duramente golpeada. 0 indivíduo é forçado a lidar com a obsolescência quase momentânea. É difícil manter o sentido da continuidade histórica, que serve de referência à formação da identidade,

* Licenciada em Pedagogia e História; Mestre em Educação. Docente da Unifil e do Instituto Superior de Educação Mãe de Deus. Londrina- PR. E-mail: monirela@sercomtel.com.br 
diante do fluxo de efemeridades da acumulação flexível (PALANGANA, 1998, p. 137138; p. 135-136).

As reflexões apresentadas neste artigo são resultados das experiências obtidas na docência, ao longo da caminhada profissional que tenho trilhado e da pesquisa de Mestrado concluída no Programa de Pós-Graduação em Educação da Universidade Estadual de Maringá-Pr. 0 referido estudo consistiu na tentativa de encontrar novas perguntas para arcaicas perguntas e respostas referentes à formação de conceitos durante o processo de ensino-aprendizagem da História. Especificamente na pesquisa, o objetivo foi o de averiguar se as transformações sócio-históricas procedentes das três Revoluções Industriais submetem à lógica do mercado a conceituação do tempo veiculado pelo livro didático de História adotado em $88 \%$ das Escolas Públicas de Londrina na, $4^{\mathrm{a}}$ série do Ensino Fundamental.

Em linhas gerais, pôde ser constatada a proximidade da conceituação do tempo na obra analisada à quantificação do tempo característica da sociedade Capitalista. A lógica formal, que impera na referida sociedade, circunscreve o tempo a uma concepção moderno-mecânica.

Uma alternativa para este entrave consiste na compreensão de que os conteúdos escolares contidos no livro didático, dentre eles o tempo, precisam considerar as características sócio-históricas das sociedades estudadas. Para que isto ocorra, o trabalho e o tempo histórico precisam estar caracterizados como eixos, pelos quais a análise histórica deve ocorrer.

\section{A formação do conceito de tempo e o trabalho}

A literatura específica dos conteúdos a serem trabalhados na área da História com as crianças, tem enfatizado que ao mediar a formação do conceito de ambiente, os professores precisam ter claro o envolvimento dos componentes físico e social do ambiente.

Neste sentido, Arribas Lleixà; et alii (2004) evidenciam a necessidade dos educadores empreenderem o trabalho de aproximação do conhecimento de linguagens, critérios, valores, normas e costumes formadores do ambiente cotidiano das crianças. É preciso ser esse o ponto de referência. Deve-se também 
ser levado em conta elementos, fatos, acontecimentos e informações que, embora longe de seu campo de ação, estão próximos de seu campo vivencial.

Assim, além dos elementos relativos ao ambiente natural, como a diversidade de objetos, de materiais (metálicos, de madeira, de plástico, de cartolina, etc.); as propriedades inerentes aos objetos (forma, tamanho, cor volume, temperatura) e aos materiais (fragilidade, dureza, permeabilidade, transparência, etc.); ou ainda a variedade dos organismos (animais, plantas, incluindo a categorização destes); são imprescindíveis a formação de conceitos relativos à identidade da criança, a organização da vida humana, os costumes, as tradições, o patrimônio cultural (Folclore) e os antecedentes culturais (memória).

0 veículo que deverá permitir a formação dos conceitos históricos, anteriormente mencionados, é o tempo. Para Varela (2004), na História (disciplina) o tempo precisa conter duas subcategorias para atuar de modo adequado como formador dos conceitos históricos.

A primeira, a do tempo cronológico (referencial para a localização temporal necessária à compreensão da História), pode ser ampliada para 0 tempo biológico (crescimento, envelhecimento); o tempo psicológico interno dos indivíduos (idéia de sucessão, de mudança); o tempo cronológico astronômico (sucessão de dias e noites, de meses e séculos).

A outra subcategoria é a do tempo como uma determinada temporalidade (tempo histórico, relações sócio-históricas de uma determinada sociedade, tempo de duração) . 0 tempo nesta dimensão deixa de ser exclusivamente evento e sucessão e passa a incorporar a simultaneidade e a repetição. "Ele se distancia da mera sucessão do calendário, preservando-a, e distancia-se da temporalidade do tempo social, inspirando-se nela" (REIS, 1994, p. 117).

Desta forma, a aprendizagem possibilitará aos alunos a análise, o contraponto, pela da observação das mudanças/permanências e das diferenças/semelhanças. 0 importante é assinalar que a contagem do tempo é essencialmente uma conceitualização da estrutura social determinada pela ação dos homens no conjunto da humanidade. 0 tempo deverá ser concebido como uma convenção social, não apresentando, portanto, qualquer significação absoluta ou universal.

A apreensão do tempo se constitui em um dos elementos determinantes da concepção de homem que o sujeito forma. A linguagem é mediadora neste processo. Esta torna-se meio de generalização e de transmissão do conhecimento 
e da experiência prática e social da humanidade. Palangana (2001, p. 104) entende que a apropriação dos conceitos e conteúdos veiculados pela linguagem ocorre "[...] num contexto social e historicamente determinado e, desse modo, sofre a influência de todas as circunstâncias materiais próprias ao estágio de desenvolvimento da vida dos indivíduos em sociedade".

A formação de um conceito científico é determinada pelos instrumentos lingüísticos e pela experiência sócio-cultural do sujeito. 0 pensamento está sujeito às leis que orientam a transformação da cultura e poderá sofrer "[...] tantas transformações quantas se registram na história das relações sociais entre os homens" (p.106).

0 conceito de tempo foi um dos elementos expropriados do sujeito durante as três Revoluções Industriais e, de modo definitivo, a sua banalização tornouse um dos princípios para a afirmação da lógica capitalista.

Desde a primeira fase da Revolução Industrial (1750-1850), houve a limitação e parcialização da atividade intelectiva do homem. Do trabalho, foi retirado o seu valor em si e the foi atribuído o valor de troca. Para que este valor do trabalho (o valor de troca) se tornasse a única possibilidade para 0 entendimento do próprio trabalho, pari passu à mencionada coisificação deste, ocorreu a crescente expropriação do conhecimento do processo produtivo, que antes era de domínio do trabalhador, mediante a separação entre execução e concepção durante 0 trabalho. A solidificação do fundamento maior da sociedade capitalista, a compra e a venda da força de trabalho, envolve inúmeros elementos que participam de sua concretização. 0 tempo apreendido no mundo moderno participou de forma decisiva neste processo, pois solidificou a força da maquinaria e enfraqueceu o trabalho humano.

Marx (1984) torna evidente que o primeiro fundamento da ordem capitalista instala-se com o emprego da manufatura (a compra e venda da força de trabalho), será mantido durante as três grandes mudanças no processo produtivo. Logo, as mudanças internas serão mais acentuadas na passagem da manufatura para a maquinaria.

Ainda na instauração da manufatura, a supressão do tempo e do espaço do trabalhador se constituiu um dos elementos garantidores do incremento da força produtiva acarretando: a aceleração do ritmo do trabalho; o isolamento do sujeito durante o processo de produção; a fragmentação do processo produtivo. 
O controle e a previsão do tempo tornaram-se normas para a produção das mercadorias manufaturadas. Desta maneira, a lógica formal, característica da sociedade industrial, lançou seus tentáculos em todos os âmbitos da sociedade e submeteu a apreensão do tempo a um conceito naturalizado, desprovido de História e relativo apenas à sobreposição de acontecimentos que, estruturalmente, caminha de maneira linear, progressiva e retilínea.

A duração rígida do tempo (tempo mecânico) acompanha a positivisação do pensamento oriunda da lógica formal. 0 tempo apreendido desta maneira, confere aos fenômenos da sociedade capitalista uma naturalidade que impede o conhecimento sobre a realidade sócio-histórica da sociedade. Ramos (1981) entende que esta naturalização dos conceitos e do próprio tempo é uma determinação da apreensão do tempo inaugurada com o capitalismo: o tempo quantitativo.

A exacerbação da divisão do trabalho ocorreu durante a Segunda Revolução Industrial (1880-1945), com a passagem da grande indústria para a automação rígida. Uma vez mais, o sujeito perde na sua experiência cotidiana o tempo e o espaço necessários ao entendimento dos conceitos na sua totalidade (dimensão sócio-histórica). As probabilidades de apreensão do tempo diferente do regularizado, do cadenciado, do cronometrado, do mercadologizado passa a ser impraticável. Com isso, o próprio pensamento se torna confinado à fragmentação característica à lógica formal pois, o tempo, como uma categoria que, dentre outras atribuições, deve possibilitar ao sujeito o entendimento do todo. Fragmentado de maneira extrema, torna-se praticamente incomensurável, fato que conferiram àqueles que dominam o controle do tempo, a sua aceleração. No bojo da fragmentação do tempo, esmigalham-se os sentidos e significados portadores da possibilidade de análise da História.

Com a Terceira Revolução Industrial e/ou automação flexível (décadas de 60/70 do século XX), não houve alteração nos fundamentos da sociedade capitalista. A força de trabalho continuou a ser comprada e vendida e não ocorreu a união entre a concepção e a execução no trabalho. As máquinas tiveram alterações e passaram a ser acopladas, reacopladas e informatizadas. Neste contexto, expressões como transitoriedade e efemeridade circunscrevem, na realidade, a experiência do sujeito ao pragmatismo imediatista da automação flexível.

Costa (2003) apresenta a mudança que a apreensão do tempo pelo 
sujeito sofre a partir da terceira Revolução Industrial. Mais uma vez, a cristalização do conceito do tempo no molde quantitativo torna aparente a impossibilidade de defini-lo de outra maneira. Esta forma de apreender 0 tempo consolidou a simultaneidade e a ocultação deste tempo, fatores necessários à reunião de tarefas parciais, iniciadas com a introdução da tecnologia e da flexibilidade no processo produtivo.

0 sentimento de normalidade diante da confusão entre a realidade e a virtualidade é uma marca crescente da nova apreensão que os sujeitos tiveram do tempo a partir da Terceira Revolução Industrial. No chão da fábrica, a palavra-chave resultante da flexibilidade e da integração é a efemeridade. $\mathrm{Na}$ vida cotidiana, a transitoriedade dos acontecimentos apresentados como distantes dos sujeitos resultará na indiferença diante da tragédia humana, como se não the fosse própria.

0 indivíduo é forçado a lidar com a obsolescência quase momentânea. É difícil manter o sentido da continuidade histórica, que serve de referência à formação da identidade, diante do fluxo de efemeridades da acumulação flexível (PALANGANA, 1998, p. 137-138).

Esta peculiaridade na apreensão do tempo, característica da sociedade Capitalista, adentrou no processo educativo de variadas maneiras, dentre essas, nos conceitos veiculados pelos livros didáticos de História.

\section{Por uma história temática: 0 tempo (pelo trabalho)}

Dentre os objetivos específicos do ensino de História, previstos nos PCNs (BRASIL,1997), está a constituição da noção de identidade social que aparece como o mais relevante. Neste sentido, torna-se necessário que o ensino de História estabeleça relações entre identidades individuais, sociais e coletivas. As recomendações previstas nos PCNs para a constituição da identidade nacional prevêem a necessidade da abrangência dos estudos históricos que devem circunscrever três aspectos fundamentais. Primeiro, refere-se à formação da identidade social: 
[...] a inclusão da constituição da identidade social nas propostas educacionais para o ensino de História necessita de um tratamento capaz de situar a relação entre o particular e o geral, quer se trate do indivíduo, sua ação e seu papel na sua localidade e cultura, quer se trate das relações entre a localidade específica, a sociedade nacional e o mundo (BRASIL, 1997, p. 32).

0 segundo aspecto refere-se à questão das diferenças e semelhanças:

Do trabalho com a identidade decorre, também, a questão da construção das noções de diferenças e semelhanças. Nesse aspecto, é importante a compreensão do eu e a percepção do outro, do estranho, que se apresenta como alguém diferente (BRASIL, 1997, p. 32).

Além da identificação de diferenças próprias no grupo de convívio, para a compreensão do outro, é necessária a análise sobre aquele que vive em outro local, ou que tenha vivido em outro tempo. Já a compreensão do nós, requer a identificação de elementos culturais comuns no grupo local e comum a toda a população nacional, como também a percepção de outros grupos, próximos ou distantes no tempo e no espaço e a construção de modos de vida diferenciados.

0 terceiro aspecto refere-se à construção das noções de continuidade e permanência:

É fundamental a percep̧̧ão de que eu e o nós são distintos de outros tempos, que viviam, compreendiam o mundo, vestiam-se e se relacionavam de outra maneira. Ao mesmo tempo, é importante a compreensão de que o outro é, simultaneamente, o antepassado, aquele que legou uma história e um mundo específico para ser vivido e transformado (BRASIL, 1997, p. 33).

0 argumento defendido é o de que por meio do conhecimento do outro, o estudante acabe conhecendo mais sobre si mesmo (isto num plano social), à medida que conhece diferentes formas de viver, diversas culturas em diferentes tempos e espaços. Para isto é necessário comparar situações, estabelecer relações entre as características de sua cultura, de sua região com distintas manifestações sociais. 
As alegações apresentadas até aqui enfatizam que o tempo e o espaço são dois conceitos, entre outros, que deveriam permitir aos homens a análise crítica da sociedade. Entretanto, conforme brevemente apresentado, foi justamente no interior destas transformações do mundo do trabalho que o tempo e 0 espaço foram suprimidos de todos os homens indistintamente. Desta maneira, os teóricos a serviço do capital foram moldando o trabalho característico dos dias atuais: coletivo, morto, parcial, superficial e heterônomo, sendo esta uma arma que aliena a formação do homem com vistas à emancipação dos domínios estabelecidos pelo capital.

Juntamente com o trabalho, o tempo em decorrência da coisificação sofrida na sociedade capitalista, colabora na limitação do pensamento, no entendimento da realidade e na formação da concepção de mundo e de homem que o sujeito irá formar. Todavia, o tempo pode e deve ser trabalhado em toda a sua complexidade, cuja dimensão o aluno deveria apreender paulatinamente.

0 tempo pode ser apreendido a partir de vivências pessoais, pela intuição, como no caso do tempo biológico (crescimento, envelhecimento) e do tempo psicológico interno dos indivíduos (idéia de sucessão, de mudança). E precisa ser compreendido, também, como um objeto de cultura, um objeto social construído pelos povos, como no caso do tempo cronológico astronômico (sucessão de dias e noites, de meses e séculos) (BRASIL, 1997, p. 37).

Diferente dos historiadores e/ou professores os quais aboliram qualquer possibilidade do trabalho com o tempo cronológico, por entenderem a impossibilidade dele se constituir como um instrumento necessário para a localização temporal, acredita-se que a medição do tempo seja um elemento imprescindivel para o entendimento da História.

A precisão de um cronômetro eletrônico que fraciona o tempo em partículas imperceptíveis psíquica e biologicamente sempre foi necessária em todas as sociedades? Ou a partir de um fracionamento maior do trabalho houve a paulatina necessidade do fracionamento, do tempo?

0 conceito de tempo no ensino de História está vinculado aos níveis das durações que se relacionam com a percepção das mudanças ou permanências nas vivências humanas. As mudanças podem ocorrer por acontecimento 
pontuais, como a queda de um governo. Podem ser analisadas a partir de acontecimentos que possuem durações mais longas, como na permanência das crises financeiras. Podem, ainda, ser identificadas em acontecimentos de longuíssimo tempo, como os comportamentos coletivos mais enraizados que permanecem por gerações, ou relações de trabalho que atravessam séculos.

Estes diferentes ritmos de duração temporal podem ser identificados em três grupos de tempos. 0 primeiro é o chamado "tempo do acontecimento breve [...]" que representa um momento preciso, uma data, como o início ou fim de uma guerra, por exemplo (BRASIL, 1997, p. 38). 0 segundo é o tempo da conjuntura que compreende o período de duração de um evento de média duração como um governo, os efeitos de uma epidemia, etc. 0 terceiro grupo é o chamado tempo da estrutura. Este "[...] é aquele que parece imutável, pois as mudanças que ocorrem na sua extensão são quase imperceptíveis nas vivências contemporâneas das pessoas" (BRASIL, 1997, p. 38). As durações de hábitos religiosos, de um regime de trabalho, podem ser aplicados ao tempo de estrutura.

Para a compreensão das diversas concepções de tempo como produtos culturais, torna-se necessário o acesso dos alunos, durante a escolaridade, à variedade de estudos em todas as complexidades que o estudo do tempo permite. De acordo com os PCNs, isto não significa que o professor deva ensinar formalmente, nos dois primeiros ciclos ( $1^{\mathrm{a}}$ a $4^{\mathrm{a}}$ séries), uma conceituação ou outra. Deve-se trabalhar atividades didáticas que envolvam essas diferentes perspectivas de tempo,

[...] tratando-o como um elemento que possibilita organizar os acontecimentos históricos no passado e no presente: estudar medições de tempo e calendários de diferentes culturas; distinguir periodicidades, mudanças e permanências nos hábitos e costumes de sociedades estudadas; relacionar um acontecimento com outros acontecimentos de tempos distintos; identificar os ritmos de ordenação temporal das atividades das pessoas e dos grupos, a partir de predominâncias de ritmos de tempo, que mantêm relações com os padrões culturais, sociais, econômicos e políticos vigentes (BRASIL, 1997, p. 84).

É importante, ainda, as crianças conhecerem o calendário utilizado por sua cultura, a fim de compartilharem as referências que localizam os 
acontecimentos no presente, passado e futuro. Entretanto, é preciso considerar que as ordenações do tempo, por meio de calendários, são uma construção que pode variar de uma cultura para outra.

Paralelamente, o ensino de História deve permitir o estudo do tempo como uma duração (tempo Histórico), a partir da identificação de mudanças e permanências no modo de vida das sociedades. Assim, além da localização temporal para o entendimento da História, a análise do modo específico da vida, do trabalho, da organização política e do pensamento dos homens no passado e no presente, torna-se também fundamental no processo de ensinoaprendizagem da História. Estes elementos constituem os componentes que, juntamente com as noções de fato histórico e sujeito histórico, a História requer para a análise das ações humanas espaço-temporalmente localizadas.

Os povos primitivos mediam o tempo de acordo com a duração do ciclo do trabalho e das tarefas domésticas. Neste sentido, o desprezo pelo relógio só poderia acontecer numa pequena comunidade de camponeses, pescadores, caçadores, etc., com uma estrutura comercial e administrativa incipiente, na qual as tarefas diárias parecessem se manifestar por si próprias, ou seja, pelas próprias necessidades desta típica comunidade.

Todavia, entre estes mesmos povos primitivos, poderiam ocorrer condicionantes essenciais que fizessem surgir notações de tempo diferenciadas. Estes condicionantes podem ser exemplificados como a situação de caçadores que teriam de passar algumas horas da noite para montar as suas armadilhas. Em épocas de colheitas, o trabalho de sol a sol pareceria natural numa comunidade de agricultores. A notação do tempo, nestes contextos, é entendida como sendo "obrigações da profissão". (THOMPSON, 1991, p. 48)

Para que se compreendam as obrigações da profissão, torna-se necessária à compreensão de três elementos. 0 primeiro deles se refere ao fato de que nos exemplos citados anteriormente (o caçador e a comunidade de agricultores), os envolvidos parecem atender uma necessidade concreta. "[...] trata-se de uma coisa mais humanamente compreensível que o tempo medido pelo relógio" (THOMPSON, 1991, p. 48).

0 segundo consiste no fato de que as relações sociais e de trabalho estão interligadas, não caracterizando um conflito entre 0 trabalho e 0 passar o tempo. "[...] numa comunidade em que a obrigação da profissão 
é comum verifica-se pouca demarcação entre o trabalho e a vida" (THOMPSON, 1991, p. 48).

Finalmente, para aqueles que trabalham pelo relógio, o sentido do seu trabalho parece deixar de existir, "[...] a obrigação da profissão parece ser inútil e sem caráter de urgência" (THOMPSON, 1991, p. 48).

A grande questão, ou complicação que se apresenta é quando se trata de estabelecer as obrigações da profissão numa relação mais complexa baseada na venda da força de trabalho (base da sociedade capitalista moderna), inédita nas sociedades até o século $\mathrm{XV}$, aproximadamente.

Numa relação que tem por base a compra e a venda da força de trabalho, os envolvidos no processo de produção experimentam a distinção entre o tempo do patrão e o tempo do empregado. Assim, o empresário sente a necessidade de utilizar o tempo de seus empregados visando o não desperdício. 0 trabalho, ou a atividade deixa de ser o princípio do próprio trabalho. 0 que se pontifica é 0 valor do tempo reduzido a dinheiro. "0 tempo torna-se dinheiro - não passa, gasta-se". (THOMPSON, 1991 , p. 49)

De maneira geral, o conceito de tempo característico da sociedade capitalista industrial, cada vez mais efêmero, participa da construção da necessidade do tempo entendido como mercadoria a ser vendido e consumido, posto em uso sem desperdício.

Assim, como existe sob a forma cada vez mais eficiente um nivelador, o capital, para avaliar a produtividade; há também uma única medida para indicar o ritmo de produção. Os novos modos de produção na sociedade capitalista exigem a medida do tempo de trabalho com precisão. É preciso dividir a tarefa, impor uma cadência constante na produção. Urge, então, a cronometria, a transformação do tempo de trabalho, um tempo medido, o que torna possível, aliás, o preço da mercadoria, o preço do trabalho. A acumulação do capital exige a acumulação do tempo do trabalho que supõe acumulação temporal. [...] Tanto faz acumular tempo ou dinheiro, os dois são reversíveis, compõem um mesmo processo; o de produção de mercadorias (RAMOS, 1981, p. 43-44).

Thompson (1991) afirma a impossibilidade por parte dos trabalhadores de simplesmente deixarem o tempo passar. Isto porque na lógica do mercado, o tempo não pode ser entendido a partir das várias dimensões que carrega consigo, de vivências pessoais, pela intuição, como no caso do tempo biológico 
(crescimento, envelhecimento); do tempo psicológico interno dos indivíduos (idéia de sucessão, de mudança); do tempo cronológico astronômico (sucessão de dias e noites, de meses e séculos); e principalmente, no caso específico da História, como um objeto de cultura, um objeto produzido socialmente pelos homens em sociedade.

A lógica que se constituiu na sociedade capitalista industrial, em se tratando do conceito do tempo, colaborou para a naturalização do conceito cronológico linear progressivo do tempo como a única possibilidade de conhecimento do tempo. No entanto, o tempo não deve estar limitado ao estudo da cronologia. Os acontecimentos identificados desta forma, assumem uma idéia de uniformidade, de regularidade, de sucessão crescente e acumulativa, ou seja, da lógica positivista: o progresso como um 'bem' necessário.

Perceber a relação intrínseca entre elementos que compõem a realidade se faz urgente. A produção social de um conceito não pode passar à margem da sociedade na qual ele é produzido. Se as verdades forem ditadas pela lógica formal (razão instrumental), o conteúdo reconstruído será fragmentado. Ocorrerá a naturalização do conteúdo e a carência da explicação que o situe devidamente como algo produzido por homens que vivem em sociedade, ou seja, o conteúdo ou o conceito resultante também das relações sociais de produção.

Na configuração da sociedade moderna, o tempo se constitui num elemento imprescindivel para a análise da realidade e para a formação da concepção de homem a ser formada pelo sujeito. Isto porque dois conceitos fundamentais que os homens devem dominar para analisarem criticamente a sociedade são justamente o tempo e o espaç̧. Entretanto, o capitalismo, por meio das três grandes Revoluções no processo produtivo, suprimiu estas categorias do indivíduo.

A partir deste ponto de vista, o processo de ensino-aprendizagem do tempo em todas as suas dimensões, inclusive o tempo cronológico, deve possibilitar 0 entendimento do próprio tempo histórico, na medida em que for desnaturalizado, sendo entendido como resultante das ações humanas diante das necessidades produzidas por sociedades em diferentes tempos históricos e cronológicos.

A tese aqui defendida é que não deve ser abolido o estudo do tempo cronológico na escola, porque este se constitui um instrumento necessário para a localização temporal, imprescindível para o entendimento da História e, que deve e pode ser analisado diferente da lógica formal positivista (linear- 
progressiva), devendo ser entendido pelo ponto de vista previsto no Materialismo Histórico (Tempo dialético). Nesta perspectiva, acredita-se na possibilidade de reconhecimento da História como o relato da exploração e da resistência à exploração, ou seja, do conflito produzido pelos homens em sociedade à medida que se relacionam entre si para a sua sobrevivência, pelo seu trabalho.

0 questionamento característico das décadas de 80/90 desdobrou-se em diversas propostas para o ensino de História. Conforme apresentado nos PCNs, alguns professores optaram pela chamada História Integrada (ordenação seqüencial e processual que intercale os conteúdos da História do Brasil e da História Geral, desde a Antigüidade até nossos dias). Outros optaram pela chamada História Temática e, nesta perspectiva, desenvolveram-se as primeiras propostas de ensino de História por eixos Temáticos.

Fonseca (2003) entende que ao defender uma perspectiva multicultural, temática não se corre o risco de fazer uma apologia ao relativismo absoluto como defendem alguns críticos da História Temática.

[...] apresenta-se conteúdos quefazem parte da chamada cultura comum, permitindo a todos os alunos igualdade de acesso ao que há de mais universal e permanente nas produções do pensamento humano, mas também conhecimentos de experiências históricas específicas dos grupos e projetos representativos para a história de cada um. [...], buscam-seo respeito à diferença, à diversidade, o espírito democrático, a tolerância e asolidariedade, sem perder de vista as referências universais da cultura, dos problemas e da história dos homens (FONSECA, 2003, p. 35).

Dentro deste leque de possibilidades, Fonseca (2003) destaca algumas perspectivas trilhadas pelas histórias ensinadas: a concepção curricular temática e multicultural. A consolidação da pluralidade de concep̧̧ões teóricas, políticas, ideológicas e metodológicas no ensino de história ocorre nas redes pública e privada. A evidência desta pluralidade, que emerge desde a orientação dos PCNs e que é observada nas escolas, requer algumas considerações.

Nestes termos, Fonseca (2003), em primeiro lugar, alerta que não basta introduzir novos temas no currículo sob uma perspectiva multicultural sem antes auscultar o currículo real reelaborado no cotidiano escolar. Além disso, é preciso reconhecer que o professor fala a sujeitos historicamente constituídos, 
repletos de crenças, significados, valores, atitudes. Assim, diversificar as fontes históricas - ir além do livro didático- possibilita o reconhecimento e o confronto de diferentes visões, além de estimular ao estudo da história, a complexidade da cultura e da experiência histórica.

Em terceiro lugar, Fonseca (2003) entende que a perspectiva temática, presente nos PCNs, deve vir acompanhada de uma mudança pedagógica na formação inicial e continuada do docente. Isto porque, a cada dia de trabalho, a formação específica que fora iniciada na licenciatura - no caso de professores - tem continuidade ao longo da vida e, sobretudo, na ação que se dá na experiência do trabalho docente. Em muitos casos, os professores não têm tempo para a reflexão requerida para a continuidade de sua formação.

Finalmente, a autora chama atenção para a necessidade dos professores de História repensarem o papel formativo do ensino de História, de entendê-la "[...] como saber disciplinar que tem um papel fundamental na formação da consciência histórica do homem, sujeito de uma sociedade marcada por diferenças e desigualdades múltiplas". (FONSECA, 2003, p. 37-38) Para ela a História é

[...] o estudo da experiência humana no passado e no presente. A história busca compreender as diversas maneiras como homens e mulheres viveram e pensaram suas vidas e a de suas sociedades, através do tempo e do espaço. Ela permite que as experiências sociais sejam vistas como um constante processo de transformação; um processo que assume formas muito diferenciadas e que é produto das ações dos próprios homens. 0 estudo da história é fundamental para perceber 0 movimento e a diversidade, possibilitando comparações entre grupos e sociedades nos diversos tempos e espaços. Por isso, a história ensina a ter respeito pela diferença, contribuindo para o entendimento do mundo em que vivemos e também do mundo em que gostaríamos de viver (FONSECA, 2003, p. 40).

Em se tratando da Histórica temática, o debate ainda está em curso, principalmente com relação às questões sobre o tempo histórico, a revisão de sua dimensão cronológica, a análise das concepções de linearidade e progressividade do processo histórico, bem como as noções de decadência e evolução. 
A intenção deste estudo foi a de contribuir com as discussões sobre a formação de conceitos veiculados pelo ensino da História a partir da hipótese de que a concepção de tempo histórico condiciona uma determinada concepção de homem.

\section{Considerações finais}

A História Tradicional circunscreve o tempo à linearidade que, desprovida das relações materiais entre os homens, naturaliza a própria História, tornandoa fragmentada, parcial e linear. Não basta retirar dos manuais de História os nomes de heróis criados pelo discurso histórico Positivista, se a lógica pela qual se desenvolve o discurso histórico não for alterada. Se isto continuar a ocorrer, os heróis permanecerão sendo forjados pela História, só que agora invisiveis, isto é, compatíveis à temporalidade característica da sociedade na qual são produzidos: beróis virtuais. 0 poder atribuído a eles não os tornará grandes, mas enormes heróis. Este poder é também ampliado na mesma medida em que a aceleração do tempo ocorreu por meio do estudo científico aplicado à produção dos bens materiais e de consumo. Desta forma, os heróis da sociedade capitalista carregam consigo a onipotência, a onisciência, a onipresença, envoltas sob o manto do anonimato que é consagrado pela ocultação do tempo o qual esvazia a própria História.

Assim, o conceito de tempo histórico (dimensão fundamental para o entendimento da História, mas que geralmente não aparece como o fio condutor da organização e disposição dos conteúdos no livro didático de História) precisa ser desnaturalizado no processo de ensino-aprendizgem da História para não obstar o conhecimento das características sócio-históricas das sociedades estudadas. 0 tempo histórico, juntamente com o trabalho, caracteriza-se como eixo pelo qual a análise da História deve ocorrer.

De maneira geral, na História se discutem o tempo cronológico (datação e periodização), o tempo vivido (a vida do aluno) e o tempo histórico (aspetos sócio-históricos das sociedades). É fundamental que, além disso, a análise das diferentes maneiras pelas quais o trabalho foi submetido nas diversas sociedades permita conceber, entre outros elementos sócio-históricos, as alterações que a 
apreensão do tempo sofreu e sofre pelas relações de produção localizadas nas bases materiais da sociedade.

A proposta aqui defendida, é a de que o desenvolvimento do processo de ensino-aprendizagem da História, deva ter como aspiração possibilitar ao aluno o conhecimento dos fundamentos sócio-históricos da sociedade brasileira. 0 exercício do movimento estrutural da História deve necessariamente partir e se desenvolver mediante as relações materiais entre os homens, o que deverá permitir ao sujeito a análise da realidade sócio-histórica na qual ele está inserido.

Neste sentido, entender o tempo como uma construção consensual historicamente produzida e relacionada a fatores infra-estruturais (relações materiais do homem) e super-estruturais (sociais, históricos, políticos, filosóficos, morais, religiosos) pode ser um dos caminhos a ser traçado com os demais conteúdos componentes do currículo escolar. A desnaturalização do conteúdo se mostra como uma eficiente alternativa para o estabelecimento de outras formas de análise da realidade sócio-histórica, distintas daquela apregoada pela sociedade capitalista: a lógica formal.

\section{Referências}

ARRIBAS LLEIXÀ, T. (et alii). Educação infantil: desenvolvimento, currículo e organização escolar. 5. ed. São Paulo: Artmed, 2004.

BRASIL. Secretaria de Educação Fundamental. Parâmetros curriculares nacionais: história, geografia. Brasília: MEC/SEF, 1997, 166 p.

COSTA, B. C. G. da. Educação dos sentidos: a mediação tecnológica e os efeitos da estetização da realidade. In: PUCCI, B.; LASTÓRIA, L. A. C. N.; COSTA, B. C. G. da. (Orgs.). Tecnologia, cultura e formação ... ainda Auschwitz. São Paulo: Cortez, 2003. p. 115-128.

FONSECA, S. G. Didática e prática do ensino de bistória: experiências, reflexões e aprendizados. Campinas: Papirus, 2003.

MARX, K. $O$ capital. São Paulo: Difel, 1984, Livro 1, vol. I.

PALANGANA, I. C. Desenvolvimento e aprendizagem em Piaget e Vygotsky: a relevância do social. 3. ed. São Paulo: Summus, 2001. 
. Individualidade: afirmação e negação na sociedade capitalista. São Paulo: Plexus, 1998.

RAMOS, C. A. História e reificação temporal. Questões e debates. Curitiba, ano 2, n. 2, p. 37-62, jun. 1981.

REIS, J. C. Tempo, bistória e evasão. Campinas: Papirus, 1994.

THOMPSON, E. P. 0 tempo, a disciplina do trabalho e o capitalismo. In: SILVA, T. T. da. (org.). Trabalho, educação e prática social: por uma teoria da formação humana. Porto Alegre: Artes Médicas, 1991.

VARELA, S. A concepção de tempo no livro didático de bistória propagado (r) pela lógica do mercado. 2004. 224 f. Dissertação (Mestrado) - Universidade Estadual de Maringá, Maringá, 2004.

\section{The Work as bedding for the transformation of the conception of time formed from the didactic book of history}

\section{ABSTRACT}

In this article the central objective is to present a proposal for Education of History that considers the partner-historical relations effective during the process of teach-learning of History. From the defended estimated one, the contained pertaining to school contents in the didactic book, amongst them the time, need to consider the partner-historical characteristics of the studied societies. So that this occurs, the work and the historical time need to be characterized as axles, for which the historical analysis must occur.

Key-words: education of history, didactic book, historical time, work. 